\title{
Solar Powered Gravity-Feed Drip Irrigation System Using Wireless Sensor Network
}

\author{
Angelina M. Y. Ho, Hawa Ze Jaafar, Ionel Valeriu Grozescu, and Muhammad Zaharul Asyraf Bin \\ Zaharin
}

\begin{abstract}
A wireless sensor network (WSN) to automatically irrigate the crops using soil moisture content values obtained from the soil moisture sensor is designed. Gravity-feed drip irrigation is actuated according to the needs of the crop by using a relay to on a solenoid valve when the soil is dry, which is determined by soil moisture content below $60 \%$. End devices communicate with the Coordinator via XBee communication links.
\end{abstract}

Index Terms-Sensors, wireless, irrigation, solar power, ZigBee.

\section{INTRODUCTION}

Deployment of wireless sensors networks (WSN) in agriculture and food industry is still at the beginning stage [1]. Applications can be classified into five categories environmental monitoring, precision agriculture, machine and process control, building and facility automation and traceability systems. In this paper, wireless sensors were used to monitor the environment and to automate the irrigation system, all powered using solar panel. We are able to see that continual advancement in sensing and communication technologies has significantly brought down the cost of deployment and running of a feasible precision agriculture framework. Sensing and communication can now be done on a real-time basis leading to better response times.

Monitoring system which connects the wireless sensors for detecting soil moisture, temperature, carbon dioxide and illumination can be done in the field-environment and connected to the internet [2], as well as inside a greenhouse using wireless sensor and SMS technology [3]. Wake-up synchronization phase were designed to periodically collect data from fixed locations minimizing the energy consumption [4]. For example, automatic data acquisition, transmission and processing for parameters such as temperature, humidity, illumination and voltage were carried out in a red bayberry greenhouse [5] and also in a smart crop monitoring system [6]. Virtual database systems were used to view spreadsheet database of the wireless sensor network [7] and tasks were performed using

Manuscript received November 25, 2014; revised March 12, 2015.

Angelina M. Y. Ho and Hawa Ze Jaafar are with the Department of Crop Science, Faculty of Agriculture, Universiti Putra Malaysia, UPM Serdang, 43400 Selangor, Malaysia (e-mail: angelinahomeiyi@ gmail.com).

Ionel Valeriu Grozescu and Muhammad Zaharul Asyraf Bin Zaharin are with the Department of Physics, Faculty of Science, Universiti Putra Malaysia, UPM Serdang, 43400 Selangor, Malaysia. programmable scripts [8].

The automation and efficiency on environment monitoring and control in agriculture are crucial. In order to control and monitor the environmental factors, sensors and actuators are essential. However, implementations are easier under protected structure than in outdoor applications. Therefore, in this paper we will be focusing on automated gravity-feed drip irrigation system in the field with the use of solar power to open the inlet valve. Water is fed to the crops without the use of pumps. This portable system will be useful in areas where there are no sources of electricity.

\section{RELATED WORKS}

Several applications using WSN in greenhouses has been developed, most of them make use of IEEE 802.15.4 or ZigBee. Some examples are greenhouse control and monitoring system [9], an automated agriculture system to monitor and control the environment in greenhouses with melon and cabbage [10] and integration a variety of sensors which can measure substrate water, temperature, electrical conductivity, daily photosynthetic radiation and leaf wetness in real-time. Benefits came from an improved plant growth, more efficient water and fertilizer applications, together with a reduction in disease problems related to overwatering [11].

There are also greenhouse auto control systems which collect information of internal environment and plants and stores it in database, and then control automatically in a remote place by using $\mathrm{Web}$ based on the greenhouse information [12]. A greenhouse auto control system contains temperature and humidity sensors [13] while in another system, leaf temperature sensor and leaf humidity sensor were added [14]. Both uses ZigBee based wireless sensor node. A ZigBee wireless sensor network was also designed using fuzzy control for drip irrigation which measured four parameters, soil moisture, temperature and light intensity and electrical conductivity for drip irrigation decision making [15].

\section{METHODS}

\section{A. Overview}

The diagram of the WSN system is shown in Fig. 1. It consists of a coordinator which collects data from the end devices over XBee communication links. The coordinator also acts as a decision maker to actuate the solenoid valve based on the parameters obtained. All of these devices are powered separately using $5 \mathrm{~W}$ solar panels. 


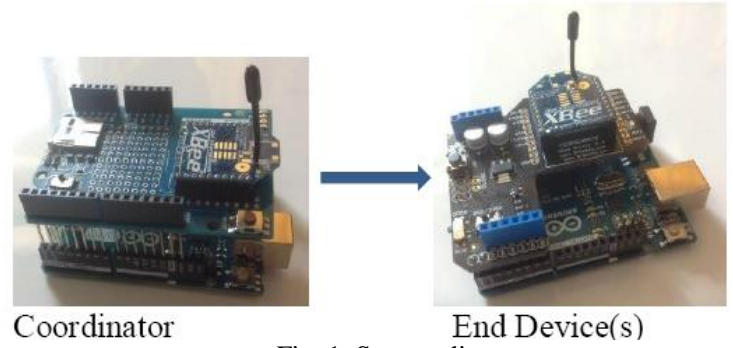

Fig. 1. System diagram.

\section{B. Design and Development}

The system is divided into two main parts as the following:

\section{1) Coordinator}

The Coordinator is the center of the system. It receives soil moisture content data from the end devices and decides if the solenoid valve should be open or close. The hardware of the Coordinator consists of an Arduino Uno, Wireless SD shield, XBee S2, relay, power module and solenoid valve as shown in Fig. 2. It also saves the data in a memory card for future trouble-shooting. The flowchart of Coordinator is shown in Fig. 3.
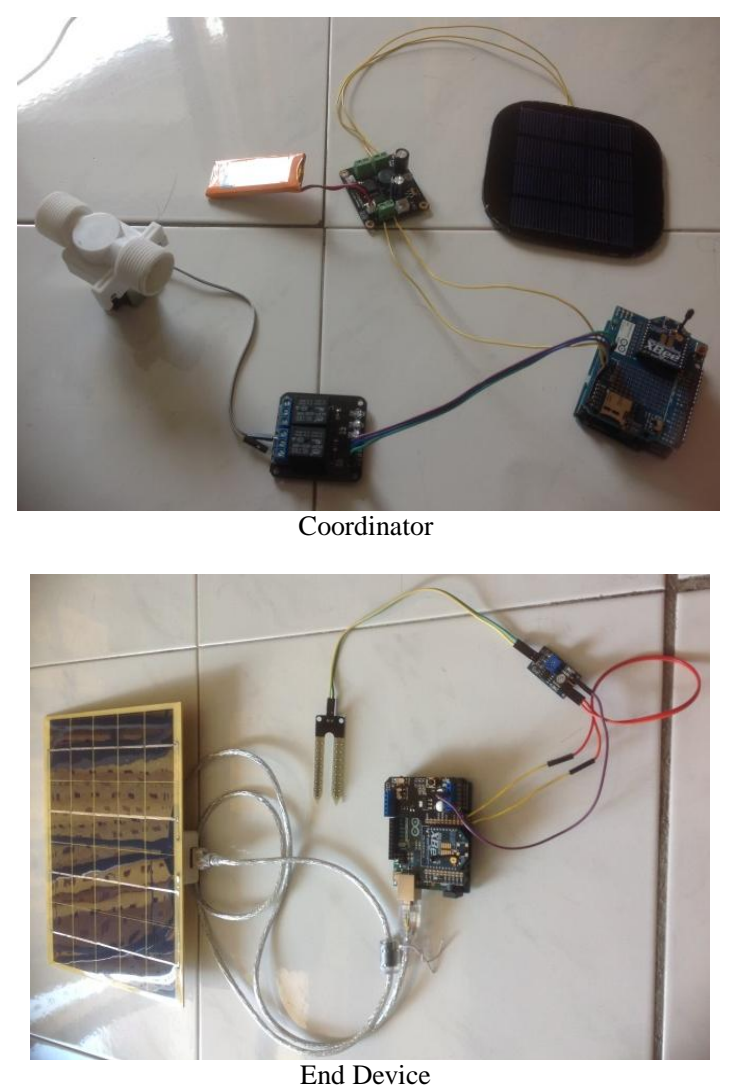

Fig. 2. Hardware Platforms of Coordinator and End Device.

\section{2) End device}

Each End Device has a soil moisture sensor and functions as shown in Fig. 3. The device collects data from the sensor at an hourly interval and sends the information to the coordinator. The End Device consists of an Arduino Uno, XBee shield, XBee 2, and soil moisture sensor as shown in Fig. 2. The soil moisture content signal in Volts is read via an Arduino Analog Input pin and converted into digital value in the range $0-1023$, where 0 represents $0 \mathrm{~V}$ and 1023 represent $5 \mathrm{~V}$. We can convert the soil moisture content value in Volts into percentage by using the mapping function to convert the digital value in the range of $0-100$ instead.

A plastic enclosure is used to cover all the components mentioned for both Coordinator and End Device.

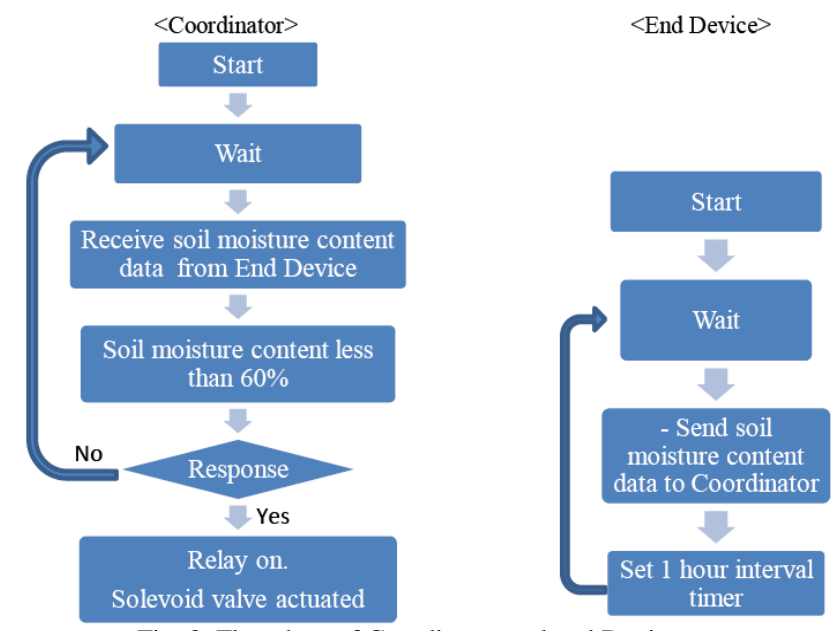

Fig. 3. Flowchart of Coordinator and end Device.

\section{System Specification}

1) Network specification

a) Star topology: Consists of a Coordinator at the centre of the network which gathers sensor readings from all End Devices. A ZigBee transmitter which operates within the ISM band of $2.4 \mathrm{GHz}$ is used. The network nodes are powered by batteries that are recharged with energy harvested from the environment using small solar cell charging circuit (Fig. 4).

2) Hardware and software specification: A WSN node consists of a microcontroller, sensor, and a communication module.

a) Microcontroller: Arduino Uno board is used which consists of the chip ATMEGA328 as a processor. The program code for Coordinator and End Device is written using Arduino IDE and uploaded onto the processor using the computer via USB port. Arduino Uno has 5 Analog I/O pins and 13 Digital I/O pins.

b) Sensor: The Soil Moisture Sensor comes in 2 parts, sensor probes and module board. The sensor is basically two probes to be inserted into soil. This sensor uses the two probes to pass current through the soil, and then it reads that resistance to get the moisture level. The sensor read $5 \mathrm{~V}$ when soil is dry and decreases to $0 \mathrm{~V}$ when soil moisture content increases. A constraint value is applied within the range of 300-1023 and mapped to read 100-0 percentage soil moisture content.

3) Communication: XBee Series 2 version is used. It operates within the ZigBee protocol and ISM $2.4 \mathrm{GHz}$ frequency band. It requires minimal power and provides reliable delivery of data between remote devices.

4) System Limitation: The outdoor line of sight distance between the Coordinator and End device should not exceed 1500 meters from the specification. On the other hand, if there are any blockages, the distance should not be greater than 60 meters. For the sensor, it can measure the soil moisture content to the accuracy of only one decimal point. 


\section{Sensor Testing}

Soil moisture sensor is connected to the Arduino analog input pin. We observe the soil moisture content readings on Arduino IDE screen monitor to check the sensors. When the value is less than $60 \%$, the relay is on and the solenoid valve is open to allow for irrigation.

\section{E. 3.5. XBee's Testing}

The XBee(end device) is connected to the Arduino, and another $\mathrm{XBee}$ (coordinator) is connected to Arduino that connected the computer USB port. Both of the XBee have to configure on the first place based on the specification in Table I using the XCTU software. After both of XBee has configured, press the connection icon in the console working mode to activate the communication status.

\section{RESUlTS AND DISCUSSION}

\section{A. Field-Test Temperature Measurement}

We deployed two sensor nodes far away from each other at about 10-30 meters and performed in the Instrumentation Lab, Department of Physics, Faculty of Science, Universiti Putra Malaysia between $8 \mathrm{am}$ to $4 \mathrm{pm}$. The system collected the soil moisture content readings every 1 hour and the result is shown in Table II. From these results, we could say that the system is working in satisfaction in term of its functionality.

TABLE I: XBEE CONFIGURATION SPECIFICATION

\begin{tabular}{|l|l|l|l|l|l|}
\hline Radio & ATMY & ATDL & ATDH & ATID & API \\
\hline Coordinator & 1234 & 5678 & 0 & 1111 & Enable \\
\hline End Device & 5678 & 1234 & 0 & 1111 & Disable \\
\hline
\end{tabular}

TABLE II: SOIL MOISTURE SENSOR READINGS AND RESPONSE OF RELAY

\begin{tabular}{|l|l|l|}
\hline Hour & Soil moisture content $(\%)$ & Relay on (Yes/No) \\
\hline $8 \mathrm{am}$ & 75 & No \\
\hline $9 \mathrm{am}$ & 61 & No \\
\hline $10 \mathrm{am}$ & 58 & Yes \\
\hline $11 \mathrm{am}$ & 83 & No \\
\hline $12 \mathrm{pm}$ & 73 & No \\
\hline $1 \mathrm{pm}$ & 69 & No \\
\hline $2 \mathrm{pm}$ & 57 & Yes \\
\hline $3 \mathrm{pm}$ & 81 & No \\
\hline $4 \mathrm{pm}$ & 73 & No \\
\hline
\end{tabular}

\section{B. Transmitting Data Wirelessly}

Since we separated both of the XBee's about 10-30 meters and let them communicate. The end device XBee was transmitted the soil moisture data collected from the Arduino to the coordinator XBee in the form of frames and the result shows in Fig. 4. From these result, we can conclude that the communication between the XBee was successful.

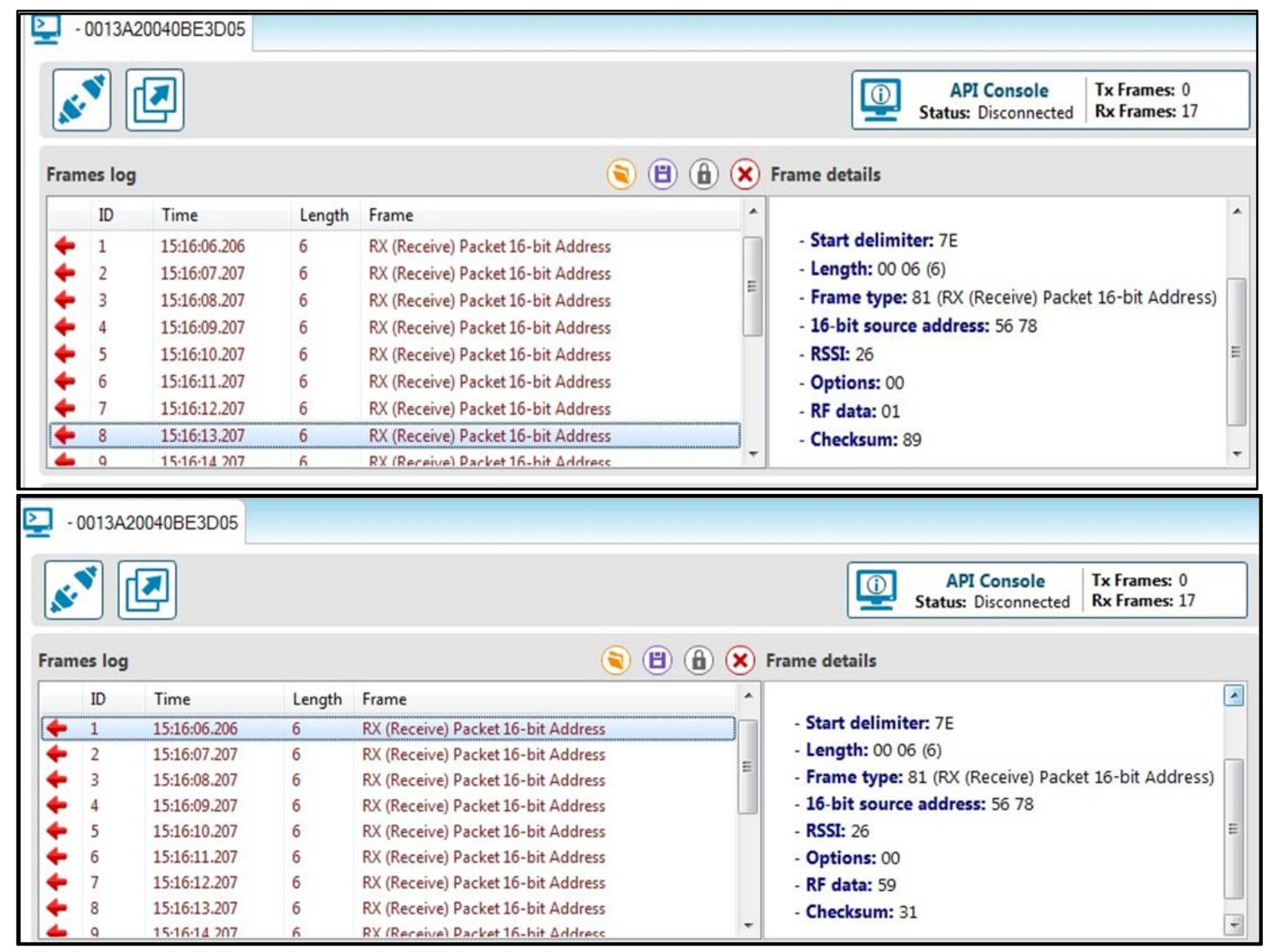

Fig. 4. The Frames that receives by the coordinator (Top: when the soil moisture is low; Bottom: when the soil moisture is high).

\section{SUMMARY AND FUTURE WORK}

Deployment of the system in the field and its effect on the yield and quality of the crop is to be tested. Currently, we are working to include fuzzy control of parameters like ambient temperature, relative humidity, and solar radiation to increase the accuracy of the rate of irrigation. The hourly data can also be used for crop modelling work.

A mesh network can be used instead of star topology as more nodes are used to cover a larger area. Price for each node can be reduced by removing the Arduino Uno board. Each wireless sensor node can be equipped with an XBee 
module alone without a microcontroller. This can be done because the XBee module can automatically sample the sensor inputs and report back to the coordinator. It is called ZigBee I/O Sampling that is XBee module can read sampling values on its pin by itself.

Since the XBee already start to communicate within the coordinator and end note by sending the data in the form of frames, and every frames that coordinator receives have to analyse. The next step would be to design a LabVIEW programming to analyse the frames and display it.

\section{ACKNOWLEDGEMENTS}

The authors would like to thank Universiti Putra Malaysia in which this research is conducted for the facilities provided.

\section{REFERENCES}

[1] C. Wang, C. Zhao, X. Qiao, X. Zhang, and Y. Zhang, "The design of wireless sensor networks node for measuring the greenhouse's environment parameters," Computer and Computing Technologies in Agriculture, Springer, vol. 2, pp. 1037-1046, 2008.

[2] H. Liu, Z. Meng, and S. Cui, "A wireless sensor network prototype for environmental monitoring in greenhouses," in Proc. WiCom 2007 Wireless Communications, Networking and Mobile Computing International Conf., 2007, pp. 2344-2347.

[3] I. A. Aziz, M. H. Hasan, M. J. Ismail, M. Mehat, and N. S. Haron, "Remote monitoring in agricultural greenhouse using wireless sensor and short message service (SMS)," Int J Eng Technology, vol. 9, no. 9, 2009.

[4] H. Sahota, R. Kumar, A. Kamal, and J. Huang, "An energy-efficient wireless sensor network for precision agriculture," in Proc. ISCC IEEE Symposium on Computers and Communications, 2010, pp. 347350.

[5] J. Xia, Z. Tang, X. Shi, L. Fan, and H. Li, "An environment monitoring system for precise agriculture based on wireless sensor networks," in Proc. $7^{\text {th }}$ International Conf. on Mobile Ad-hoc and Sensor Network, 2011, pp. 28-35.

[6] Z. Liao, S. Dai, and C. Shen, "Precision agriculture monitoring system based on wireless sensor networks," in Proc. ICWCA International Conf. on Wireless Communications and Applications, 2012, pp. 1-5.

[7] S. Hadim and N. Mohamed, "Middleware challenges and approaches for wireless sensor networks," IEEE Distrib. Sys. Online, vol. 7, no. 3, 2006.

[8] C. Srisathapornphat, C. Jaikaeo, and C. Shen, "Sensor information networking architecture," in Proc. 2000 International Workshops on Parallel Processing Proceedings, 2000, pp. 23-30.
[9] L. Gonda and C. E. Cugnasca, "A proposal of greenhouse control using wireless sensor networks," in Proc. $4^{\text {th }}$ World Congress Conference on Computers in Agriculture and Natural Resources, Orlando, Florida, USA, 2006.

[10] S. Yoo, J. Kim, T. Kim, S. Ahn, J. Sung, and D. Kim, "Automated agriculture system based on WSN," in Proc. ISCE 2007 IEEE International Symposium on Consumer Electronics, 2007, pp. 1-5.

[11] J. D. Lea-Cox, G. Kantor, J. Anhalt, A. Ristvey, and D. S. Ross, "A wireless sensor network for the nursery and greenhouse industry," in Proc. Southern Nursery Assoc. Research Conf., 2007, pp. 454-458.

[12] Z. Yiming, Y. Xianglong, G. Xishan, Z. Mingang, and W. Liren, "A design of greenhouse monitoring \& control system based on ZigBee wireless sensor network," in Proc. WiCom International Conference on Wireless Communications, Networking and Mobile Computing, 2007, pp. 2563-2567.

[13] B. Kang, D. Park, K. Cho, C. Shin, S. Cho, and J. Park, "A study on the greenhouse auto control system based on wireless sensor network," in Proc. SecTech 2008 International Conference on Security Technology, 2008, pp. 41-44.

[14] D. H. Park, B. J. Kang, K. R. Cho, C. S. Shin, S. E. Cho, J. W. Park, and W. M. Yang. (January 2011). A study on greenhouse automatic control system based on wireless sensor network. Wireless Personal Communications. [Online]. Available: http://link.springer.com/article/10.1007/s11277-009-9881-2

[15] X. Xiang. (2011). Design of fuzzy drip irrigation control system based on ZigBee wireless sensor network. Computer and Computing Technologies in Agriculture IV. [Online]. pp. 495-501. Available http://link.springer.com/chapter/10.1007/978-3-642-18333-1_58

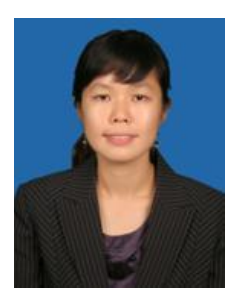

Angelina M. Y. Ho was born in Negeri Sembilan, Malaysia on November 15, 1984. She obtained her bachelor degree in agriculture engineering in 2008 at Universiti Putra Malaysia, Serdang. She continued her master degree in the same field with majoring in robotics and automation in agriculture and graduated in 2012. Currently, she is doing her $\mathrm{PhD}$ degree in agrotechnology at Universiti Putra Malaysia.

She worked as an intern on a lettuce and herbs farm in 2007 at Monoluxury, Genting Highlands, Malaysia. Her interest in agriculture automation led her to work under the guidance of $\mathrm{Dr}$ Mohammed Che Hussain in the Agriculture Mechanization and Automation Department, Malaysian Agriculture Research and Development Institute (MARDI) on a few controlled environment projects during her years as a masters student. Her current research is on maximizing the yield and quality of ginger using wireless sensor network and mathematical modeling.

Ms. Ho is a member of the International Socety for Southeast Asian Agricultural Sciences (ISSAAS) 